\title{
Prenatal diagnosis of a neural tube defect: Meckel syndrome
}

\begin{abstract}
Summary. A severe neural tube defect diagnosed in a $19 \frac{1}{2}$-week-old 'at risk' fetus on the evidence of a markedly elevated alpha-fetoprotein level in the amniotic fluid, turned out to be an occipital myelocoele. However, the fetus also had polycystic kidneys and postaxial hexadactyly on all extremities. The karyotype was normal. These are the features of the rare Meckel syndrome, caused by a pleiotropic, autosomal, recessive gene, and one and possibly two other sibs were also affected.
\end{abstract}

Meckel syndrome was unwittingly encountered in a fetus terminated at $21 \frac{1}{2}$ weeks' gestation following the diagnosis at $19 \frac{1}{2}$ weeks of a severe neural tube defect by assay of the alpha-fetoprotein content of the amniotic fluid. Such a test is now recognized as being reliable for the prenatal detection of fetuses with severe neural tube defects at a stage in pregnancy early enough to permit selective abortion (Brock and Sutcliffe, 1972; Seller et al, 1974).

\section{Case report}

Mrs K.V., aged 25 years, gravida III, para O, was referred for genetic advice to the Paediatric Research Unit at Guy's Hospital. A diagnostic amniocentesis was indicated as her two previous pregnancies had resulted in infants with encephalocoeles. Thus, she was considered to be at a 1 in 10 or greater risk of producing another infant with a neural tube defect (Roberts, 1973).

At $19 \frac{1}{2}$ weeks' gestation, the amniotic fluid alphafetoprotein level was found to be $154 \mu \mathrm{g} / \mathrm{ml}$ (normal range, $<1-16 \mu \mathrm{g} / \mathrm{ml})$. A severe neural tube defect was indicated and an ultrasound examination (by $\mathrm{Mr} \mathrm{S}$. Campbell) confirmed this. Termination was done by hysterotomy at $21 \frac{1}{2}$ weeks.

The male fetus (Fig. 1) weighed $275 \mathrm{~g}$, crown-rump length $15 \mathrm{~cm}$. He had an occipital myelocoele, micrognathia, an extensive cleft of the bony palate, and simple, lowset ears. The thorax was hypoplastic, the abdomen large and the phallus small. There were six digits on the post-axial border of both hands and feet; there was talipes equinovarus and a flexion deformity of both arms. Apart from the myelocoele through the region of the posterior foramen, and a small defect in the midline of

Received 1 July 1974.

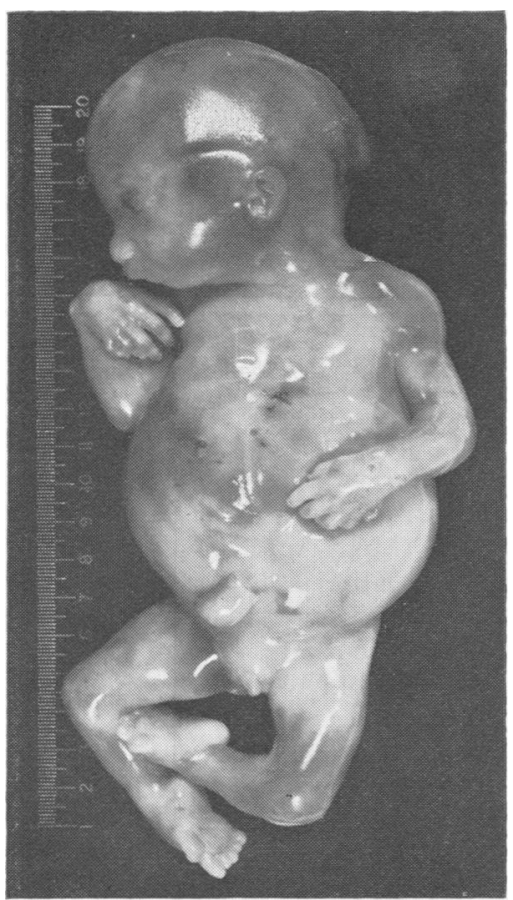

FIG. 1. Fetus with occipital myelocoele, micrognathia, polydactyly, small phallus, and enlarged abdomen with polycystic kidneys.

the occipital bone, the cerebrum seemed normal but the cerebellar fossa was abnormally steep anteriorly and excessively coned. The kidneys were enlarged and polycystic and there were large cysts close to the testes. The right ventricle was hypoplastic and the left ventricle was hyperplastic. All other organs were macroscopically normal. Chromosome studies (by Miss S. Blunt) revealed a normal $46, \mathrm{XY}$ complement.

Following these findings, more detailed information on the first two pregnancies were sought. The first had resulted in a microcephalic female, stillborn at 35 weeks of gestation, who had an encephalocoele. The second pregnancy went to term and a female infant was delivered who lived for $30 \mathrm{~min}$. She had a meningocoele with a large defect of the occipital bone and foramen magnum, and a sacral spina bifida. There was external rotation of the legs and feet, and there were six digits on the post axial side of both hands and feet. The kidneys were large and polycystic, no bladder could be found, the vagina was atretic and distended by mucus. The cerebrum showed microgyria and the cerebellum was poorly developed. She had a normal $46, \mathrm{XX}$ chromosome complement.

The parents were healthy Caucasians and there was no consanguinity. 


\section{Discussion}

There have been approximately 50 reported cases of Meckel syndrome since 1822 when Meckel first described the condition. Affected infants have multiple congenital defects including encephalocoele, microcephaly, microphthalmia, hare lip and/ or cleft palate, small genitalia, polycystic kidneys, polydactyly, and a number of minor abnormalities (Hsia, Bratu, and Herbordt, 1971; Mecke and Passarge, 1971). For a positive diagnosis of the syndrome, Fried et al (1971) suggest that at least three of the major defects should be present. Although suggestive of a chromosomal aberration, particularly trisomy 13 , the karyotype is normal, and the syndrome is thought to be due to an autosomal recessive gene (Mecke and Passarge, 1971). Affected infants are either stillborn or die shortly after birth. Both the second and third infants of this patient had multiple congenital anomalies which accord with the stigmata of Meckel syndrome. In view of the high recurrence rate in families (Fried et al, 1971; Hsia et al, 1971; Mecke and Passarge, 1971) and the fact that the first sib had microcephaly and an encephalocoele, it is possible that all three sibs had Meckel syndrome. Such a diagnosis is, of course, important for the future counselling of the patient.

I thank the Spastics Society for financial support, Dr K. Beattie, General Practitioner, and Mr J. M. Slater, Consultant Obstetrician for permission to publish details of their patient, Dr J. D. Singer for genetic counselling, and Mr L. Kelberman for photography.

Mary J. Seller

Paediatric Research Unit, Guy's Hospital Medical School, London, SE1 9RT

REFERENCES

Brock, D. J. H. and Sutcliffe, R. G. (1972). Alpha-fetoprotein in the antenatal diagnosis of anencephaly and spina bifida. Lancet, 2, 197-199.

Fried, K., Liban, E., Lurie, M., Friedman, S., and Reisner, S. H. (1971). Polycystic kidneys associated with malformations of the brain, polydactyly, and other birth defects in newborn sibs. Fournal of Medical Genetics, 8, 285-290.

Hsia, Y. E., Bratu, M., and Herbordt, A. (1971). Genetics of the Meckel syndrome (Dysencephalia splanchnocystica). Pediatrics, 48, 237-247.

Mecke, S. and Passarge, E. (1971). Encephalocoele, polycystic kidneys, and polydactyly as an autosomal recessive trait simulating certain other disorders: the Meckel syndrome. Annales de Génétique, 14, 97-103.

Meckel, J. F. (1822). Beschreibung Zweier, durch sehr ähnliche Bildungsabweichungen entstellter Geschwister. Deutsches Archiv für die Physiologie, 7, 99-172.

Roberts, J. A. Fraser (1973). An Introduction to Medical Genetics, 6th ed., p. 289. Oxford University Press, London.

Seller, M. J., Singer, J. D., Coltart, T. M., and Campbell, S. (1974). Maternal serum-alpha-fetoprotein levels and prenatal diagnosis of neural-tube defects. Lancet, 1, 428-429.
A case of hyalinosis cutis et mucosae (lipoid proteinosis of Urbach and Wiethe) with common ancestors in four remote generations

Summary. We report a case of hyalinosis cutis et mucosae, a rare disorder of hyalin deposition in skin and mucous membranes, in a 27-year-old male, whose coefficient of inbreeding was 0.0106 due to seven common ancestors, including an aunt of an early American president, in the eight preceding generations.

Hyalinosis cutis et mucosae (lipoproteinosis, lipoid proteinosis of Urbach and Wiethe) is a rare, chronic disease characterized by widespread papules, nodules, and plaques composed of hyalinized material. It may extensively involve the skin and the mucous membranes of the gastrointestinal, respiratory, and genitourinary systems, but it may occur as well in other organ systems, for instance, the central nervous system. The skin over the face, neck, and hands is frequently involved, although any area may be affected. The margins of the eyelids may present a distinct picture with papules distorting the lashes. There is predilection for lesions to occur on the mucosae of the oral cavity and upper respiratory tract. Hoarseness, which may be present at birth, is a common sign produced by infiltration of the vocal cords. Microscopically the lesions show hyalinosis, that is, thickening of the capillary walls with deposition of hyalin beneath the basement membrane and in the dermis.

Hyalinosis cutis et mucosae is presumably monogenically determined as autosomal recessive, though a genetic analysis has not been published. The purpose of this report is to describe a case of the disorder in a 27-year-old male, the only child of his consanguineous parents, whose ancestry was traced and found to include seven common ancestors, including an aunt of an early American president, in four of the preceding eight generations.

\section{Case report}

The propositus (B.D.C. 0040-01-0571) was born when his mother was 42 and his father 48 years old, the result of their only pregnancy. During the gestation the mother required surgery at six months for a uterine

Received 24 June 1974. 